\title{
REAL TIME-WATER OPTIMIZATION TECHNIQUE FOR AGRICULTURAL CROPS USING WSN AND GSM MODULE
}

\author{
S.Vithyalakshmi
}

PG Scholar, Department of Information Technology, Adhiparasakthi Engineering College, Melmaruvathur, India

\begin{abstract}
Efficient water management is the only way to avoid frazzle of freshwater. Agriculture utilizes most of the fresh water; since the atmospheric parameters vary from place to place in large farm field, it makes very difficult to maintain the uniformity in all the places of farm field manually. So a combined function of wireless sensor network (WSN) and embedded system is used to control the irrigation.The soil moisture and temperature sensors are incorporated in root zones of the plants. ZIGBEE radio modem transmits the information to master microcontroller for processing. The microcontroller is programmed with threshold values of soil moisture and temperature sensors. Automatic irrigation starts when the processed data of the microcontroller drops below the threshold value. The strain sensor is used to indicate the motor theft. A GSM module is embedded to provide the remote control of data inspection and irrigation scheduling.
\end{abstract}

Keywords: wireless sensor networks (WSNs), Zigbee, GSM, Load Cell, PIR sensor, water resources.

\section{INTRODUCTION}

The fresh water management is crucial for human being to survive the increased population which paves the high demand for food. Agriculture is the one which utilizes most of the fresh water, must be optimized in a best way to avoid the draining of natural resource. Many strategies are employed to save water such as drip; sprinkler irrigations. Irrigation is the application of water to the land soil. Agriculture is an industry that uses a lot of water. Water seems abundant on our planet; however, less than $1 \%$ of the world's liquid freshwater is available for human use and about $70 \%$ of it is used for irrigation. So it is important to minimize water loss. This has motivated studies on control of irrigation channels where water losses can be large. Automation in irrigation system generally consists of soil moisture sensor or water level sensor, a control system and irrigation system components. There are also several researches on soil moisture sensor based irrigation system. Water level sensors have application in irrigation water distribution and delivery system. The work describes about a ground water level measurement technique. In our country it is seen that unequal distribution of water in different piece of land during irrigation. There are some places where it is impossible to irrigate every day. Pump stolen is a common issue in these areas. Large amount of crops are damaged in every year due to heavy rain. The owner of the land does not get any information about rain, pump's condition when he is out of land area. An embedded GSM would give an update of the land.

\section{RELATED WORKS}

Over so many years wireless sensor network technology has tremendously indulged with the success rate in remote monitoring. Accordingly a system is designed to monitor the irrigation to the land using the diverse measure of canopy temperature. Using the thermal imaging and with the assist of embedded sensors and microcontroller irrigation is scheduled automatically [1]. The other system is enhanced with zone specific irrigation optimises the water usage as well as increases the crop yield. A precision irrigation based on closed loop zone specific data is used to provide an effective usage of water. Soil, crop and climate in the field are monitored to provide a decision support system. This is able to deliver the necessary treatment according to the monitored data [2]. The distributed in field sensor based irrigation increases the productivity while saving the water. This paper explains the detailed design of variable rate irrigation with wireless sensor network and software for real time field sensing and control of site specific precision linear move irrigation system. The Bluetooth wireless technology offers a plug and play module which saves the time as well as inexpensive [3].The GSM based drip irrigation methodology gives the facilities of maintaining uniform environmental conditions all over the green house. This system covers only lower range of agriculture land. The cost spend to develop the system is high for such low covering area. Hence it's not economically benefit [4]. WSN in climatic parameter monitoring is the energy efficient inexpensive technology. In case of long distance or impossible transport to check the actual environment conditions these networks are deployed to provide a data about the environment. Any physical parameter can be converted to electrical signal using WSN and the multihop network would transfer the data to the destination [5].

\section{EXSISTING SYSTEM}

\section{Sprinkler Irrigation}

Water is distributed through a system of pipes usually by pumping. It is then sprayed into the air and irrigates the 
entire soil surface through spray heads so that it breaks up into small water drops which fall to the ground.

\section{Drip Irrigation}

Water is allowed to drip slowly to the roots of plants, either onto the soil surface

or directly onto the root zone, through a network of valves, pipes, tubing, and emitters.

\section{Scheduling overhead irrigation}

Based on the volumetric moisture in the growing substrate, and plant Evapotranspiration (ET) the irrigation to the land is controlled.

\section{Precision linear-move irrigation system}

A distributed sensor-based site-specific irrigation system is implemented to increase yield and quality while saving water.

\section{Automatic irrigation system}

Based on soil-moisture and temperature sensors placed in the root zone of the plants, according to that value the irrigation is controlled. The remote monitoring is enabled using the

\section{PROBLEM DESCRIPTION}

Automatic irrigation systems which are in action are either cost effective or need a skilled labour (farmer) to maintain the entire equipment. The monitoring through web makes it much more expensive probably a farmer couldn't afford to and also the person must be skilled enough to configure the web page. So this come to the conclusion that the designing system must be simple and delicate more importantly it must be understood by an illiterate.

\section{PROPOSED SYSTEM}

The proposed system consists of two main functional units.

- Wireless sensor field unit (WSFU)

- Wireless control unit (WCU)

The wireless sensor field unit (WSFU) consists of a microcontroller (ARM LPC-2148), Zigbee transceiver, sensors, and power supply which is configured and deployed in the field for automatic control of water usage. The sensors are used to monitor the soil moisture, temperature and according to that the land is irrigated. The PIR sensor is the motion sensor, used to detect the animals and triggers the buzzer to scare them off the land.

The Wireless control unit (WCU) consists WIU consists of a master microcontroller (ARM LPC-2148), an XBEE radio modem, a GSM module, an RS-232 interface MAX232, two electronic relays, a DC motor and a strain sensor. The information from WSFU are analysed in WCU and actions are taken according to the processed result. The strain sensor is used to indicate the theft of motor.

\section{TRANSMITTER SECTION (WSFU)}

The transmitter section consists of microcontroller section, interfacing sections, sensors and power supply section as shown in Figure 4.1.the transmitter is placed at the land field, where the sensors are used to sense the soil moisture and temperature value in real time.

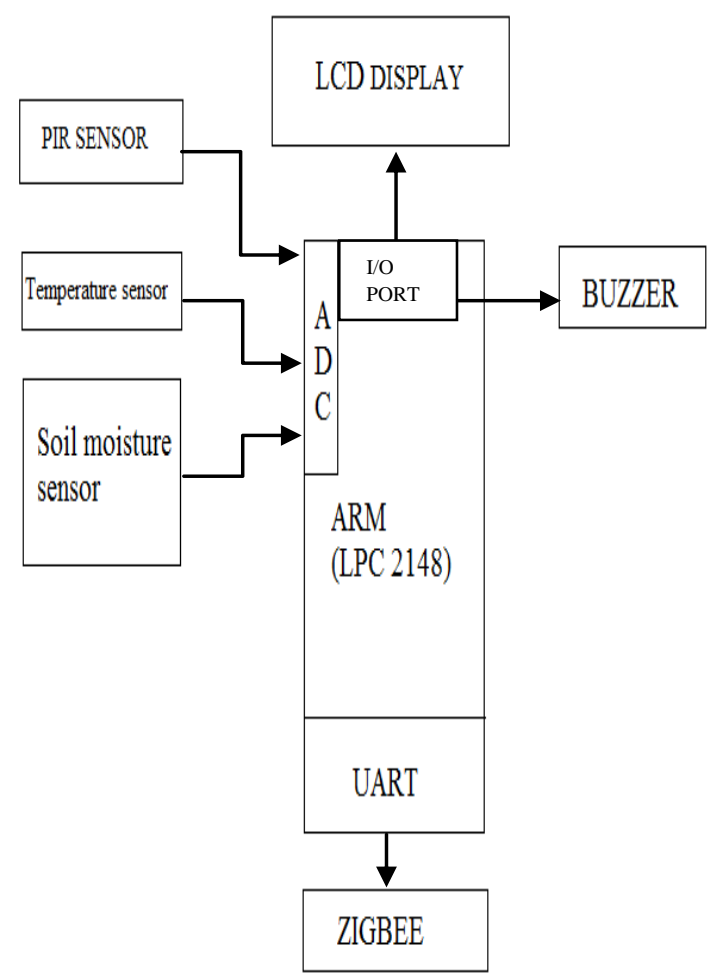

Fig 5.1- Wireless sensor field unit

The wireless sensor field unit consist of a microcontroller (ARM LPC-2148), Zigbee transceiver, sensors, and power supply which is configured and deployed in the field for automatic control of water usage.

\section{Slave Microcontroller (ARM LPC-2148)}

The LPC2148 microcontrollers are based on a 32/16 bit ARM7TDMI-S CPU with Real-time emulation and embedded trace support that combines the microcontroller with embedded high speed flash memory ranging from 32 $\mathrm{kB}$ to $512 \mathrm{~Kb}$. The sensor will provide an analog data continuously, which is converted to digital using ADC which is soldered at the controller pin. The controller will check for the abnormality. And then transmit the data to the master microcontroller via the Zigbee.

\section{Zigbee (XBee PRO Series 2 OEM)}

The XBee Series 2 OEM RF Modules were engineered to operate within the Zigbee protocol and support the unique needs of low-cost, low-power wireless sensor networks. The modules require minimal power and provide reliable delivery of data between remote devices.

\section{Soil moisture sensor}

The sensor array is accompanied with soil sensors, including moisture and temperature which are implanted in the root zones of the plants. The VH400 probe is choose to calibrate the soil moisture because of low power consumption and low cost. The probe will take the measure of dielectric constant of the soil using 
transmission line techniques at $80 \mathrm{MHz}$, it is highly resistant to water salinity also provides an output range of 0 and $3.0 \mathrm{~V}$, which is proportional to the volumetric water content (VWC). The sensor is powered at $3.3 \mathrm{~V}$ and monitored by the microcontroller through an ADC port.

\section{SET POINT $\quad-45 /-40 \quad K P a(D A Y / N I G H T)$ VWC6)}

\section{Temperature sensor}

This is used to find the deviation in temperature of the soil in the plant root zone.

\section{SET POINT - 25/20 ${ }^{\circ} \mathrm{C}$ (day/night)}

LM 35 is used because of its

$\begin{array}{ll}\text { - } & \text { Calibrated Directly in }{ }^{\circ} \text { Celsius (Centigrade) } \\ \text { - } & \text { Linear }+10 \mathrm{mV} /{ }^{\circ} \mathrm{C} \text { Scale Factor } \\ \text { - } & 0.5^{\circ} \mathrm{C} \text { Ensured Accuracy }\left(\text { at }+25^{\circ} \mathrm{C}\right) \\ \text { - } & \text { Rated for Full }-55^{\circ} \mathrm{C} \text { to }+150{ }^{\circ} \mathrm{C} \text { Range } \\ \text { - } & \text { Suitable for Remote Applications } \\ \text { - } & \text { Low Cost Due to Wafer-Level Trimming } \\ \text { - } & \text { Operates from } 4 \text { to } 30 \mathrm{~V} \\ \text { - } & \text { Less than } 60-\mu \mathrm{A} \text { Current Drain } \\ \text { - } & \text { Low Self-Heating, } 0.08^{\circ} \mathrm{C} \text { in Still Air } \\ & \text { Nonlinearity Only } \pm 1 / 4^{\circ} \mathrm{C} \text { Typical }\end{array}$

\section{PIR sensor and buzzer}

Passive Infrared Sensor (PIR) module is used for motion detection The sensor is designed to adjust to slowly changing conditions that would happen normally as the day progresses and the environmental conditions change, but responds by making its output high when sudden changes occur, such as when there is motion If there is any movement in the field the sensor would detect the motion and turn on the buzzer. In case of any human intrusion, say like someone is trying to stole the pump then also the buzzer will be on.

\section{Receiver section}

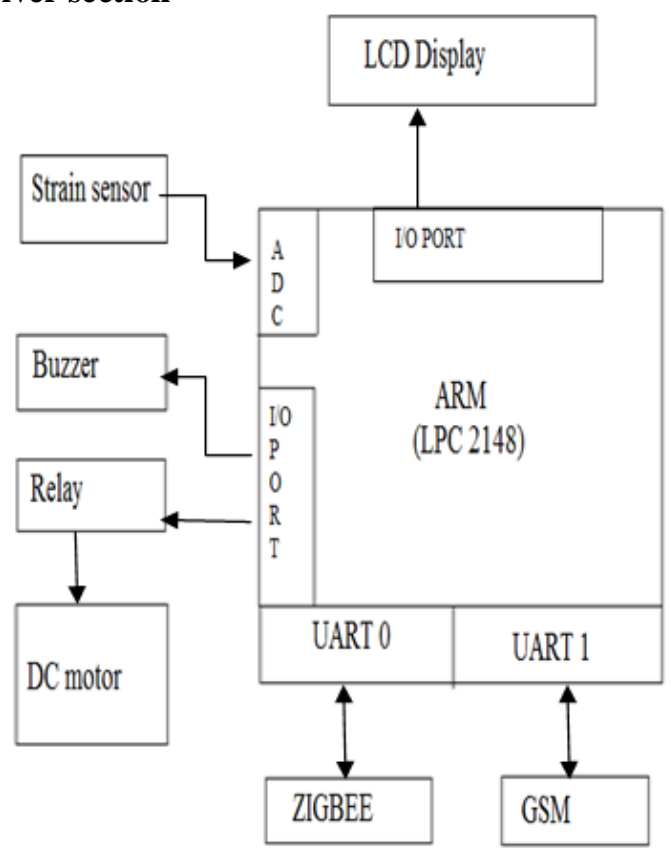

Fig 4.2 Wireless control unit
Master Microcontroller (ARM LPC-2148)

The master microcontroller receives the data from (WSFU) then compares the data with the threshold value. If the received value is less than the threshold value then irrigation is turned on automatically. The strain sensor is used to avoid the motor theft. The sensor is placed at the base of motor, where it stores the numerical load data of motor. Once the values reduce, it indicates the fact that the motor has been stolen. Which in turn triggers the buzzer as well as SMS is send to the user via GSM. Remotely the motor can be turned on and off using GSM according to user need.

\section{SIMULATION RESULT \& CONCLUSION}

KEIL $\mu$ Vision4 IDE has been designed to enhance developer's productivity, enabling faster, more efficient program development. $\mu$ Vision 4 introduces a flexible window management system, enabling you to drag and drop individual windows anywhere on the visual surface including support for Multiple Monitors. Multiple Monitor and flexible window management system is available.

Proteus8 PCB design combines the ISIS schematic capture and ARES PCB layout programs to provide a powerful, integrated and easy to use suite of tools for professional PCB. Design All Proteus PCB design products include an integrated shape based auto router and a basic spice simulation capability as standard. More advanced routing modes are included in Proteus PCB Design Level 2 and higher whilst simulation capabilities can be enhanced by purchasing the Advanced Simulation option and/or simulation capabilities

\section{IRRIGATION ACTION-1}

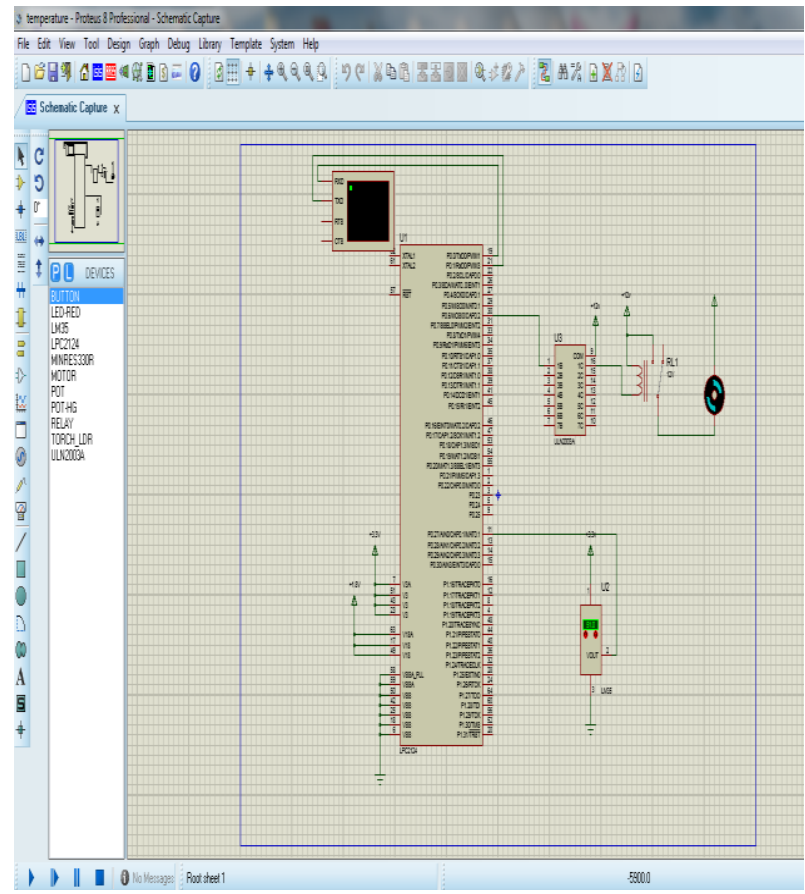

Fig 6.1 ISIS Schematic View of IA-2 
Proteus 8 is used as simulation tool. The ISIS schematic The soil moisture set point is $-45 /-40 \mathrm{KPa}$. The strain view of irrigation action-1 is shown in fig 5.1The sensor value set point is assumed as 300 . When these threshold value for temperature is set as $25 / 20^{\circ} \mathrm{C}$.

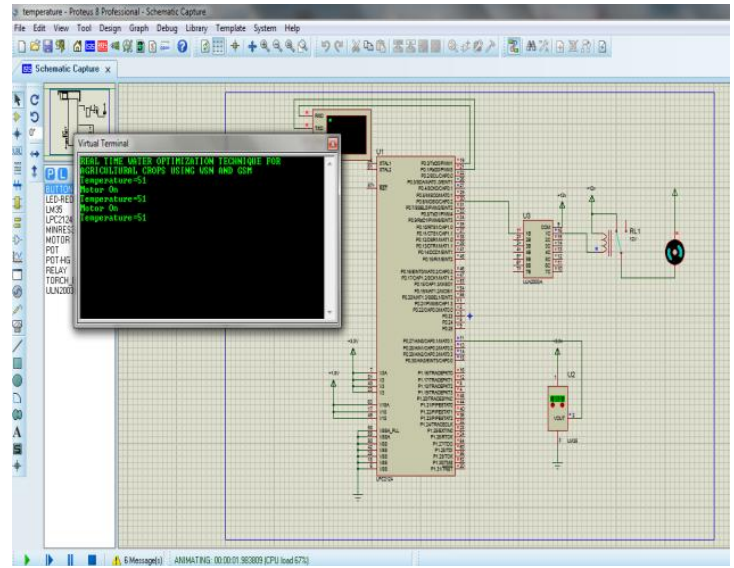

Fig 6.2 Virtual Terminal Display Of Sensed Data

The LM35 will sense the temperature at the root zone of the plant continuously. When the reading drops below or reach above the threshold value then the motor will automatically turn on/off. As shown in Fig 5.2.

\section{IRRIGATION ACTION-2}

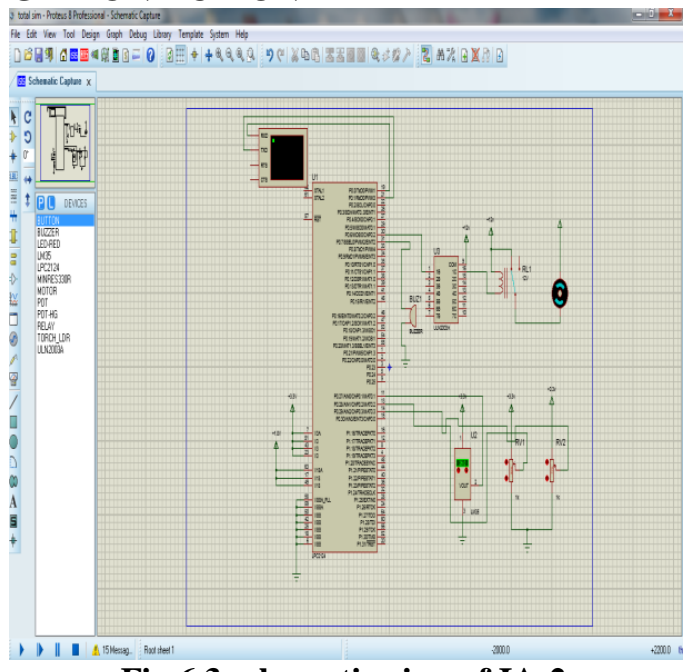

Fig 6.3 schematic view of IA-2

The ISIS schematic view of irrigation action is shown in Fig 5.3. Where the temperature, soil moisture and load cell/strain sensor comes to action.

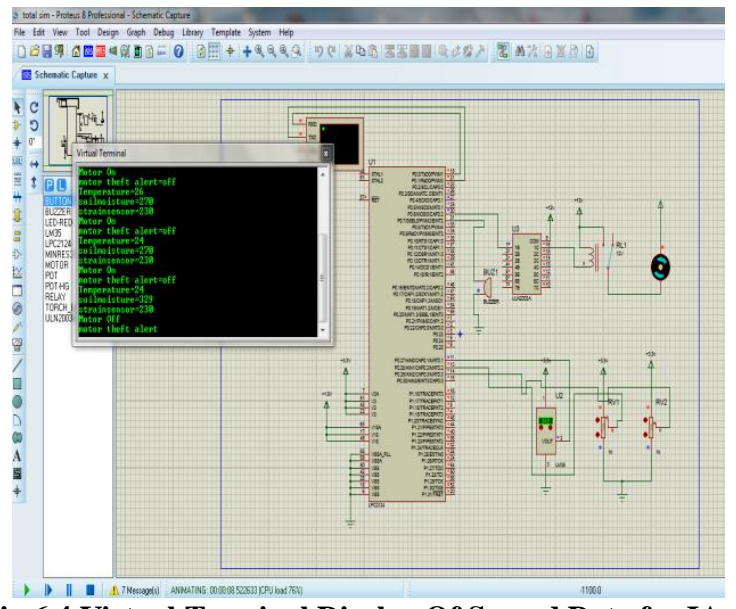

Fig 6.4 Virtual Terminal Display Of Sensed Data for IA-2 value elevate the motor will automatically on/off. And the sensor elevation will result in automatic trigger of buzzer and an indication SMS to owner in case of motor theft. As shown in fig.5.4.

\section{CONCLUSION}

The proposed system irrigation system allows cultivation in places with water scarcity thereby improving sustainability. This irrigation system can be adjusted to variety of specific crop needs. The GSM module will enable the remote on/off of irrigation. The PIR and strain sensor provide the security to pumps and motor. In case motor theft, the strain sensor will send a SMS to the owner immediately.

\section{REFERENCES}

[1] Christos Goumopoulos, Berdan O'flynn, Achilles Kameas,"Automated ZoneSpecific Irrigation with Wireless Sensor/Actuator Network and Adaptable Decision Support," IEEE TRANSACTION on Computers And Electronic In Agriculture, vol. 105, pp 20-33 March 2014.

[2] Xuezhi Wang,, Weiping Yang, Ashley Wheaton, Nicola Cooley,Bill "Efficient registration of optical and IR images for automatic plant water stress Assessment," IEEE TRANSACTION Computers And Electronic In Agriculture., vol. 74, pp 230-237 August 2010.

[3] Yoseop (James) Kim, Robert G.Evans And William M.Iverson, “ Remote Sensing And Control Of An Irrigation System Using A Distributed Wireless Sensor Network," IEEE TRANSACTION on Instrumentation And Measurement, Vol., 57, pp 7,july 2008.

[4] Daniel K.Fisher, Hirut Kebede, "A Low Cost Microcontroller Based System to Monitor Crop Temperature and Water Status," IEEE TRANSACTION on Computers And Electronic In Agriculture., vol. 74, pp 168-173 march 2010.

[5] Mohd Fauzi Othman, Khairunnisa Shazali,"Wireless Sensor Network Applications: A Study in EnvironmentMonitoring System," IEEE TRANSACTION on Intelligent Sensors, vol. 41, pp 1204-1210 August 2010.

6] K. S. Nemali and M. W. Van Iersel, "An automated system for controlling drought stress and irrigation in potted plants," Sci. Horticult. $\quad$ vol. 110, no. 3, pp. 292-297, Nov. 2006.

[7] S. A. 'Shaughnessy and S. R. Evett, Canopy temperature based system effectively schedules and controls center pivot irrigation of cotton,"Agricult. Water Manag., vol. 97, no. 9, pp. 310-1316, Apr. 2010.

[8] R. G. Allen, L. S. Pereira, D. Raes, and M. Smith, Crop Evapotranspiration-Guidelines for Computing Crop Wate Requirements-FAO Irrigation and Drainage Paper 56. Rome, Italy: FAO, 1998.

[9] S. L. Davis and M. D. Dukes, "Irrigation scheduling performance by evapotranspiration-based controllers," Agricult. Water Manag., vol. 98, no. 1, pp. 19-28, Dec. 2010.

[10] K. W. Migliaccio, B. Schaffer, J. H. Crane, and F. S. Davies, "Plant response to evapotranspiration and soil water sensor irrigation scheduling methods for papaya production in south Florida," Agricult. Water Manag., vol. 97, no. 10, pp. 1452-1460, Oct. 2010.

[11] J. M. Blonquist, Jr., S. B. Jones, and D. A. Robinson, "Precise irrigation scheduling for turfgrass using a subsurface electromagnetic soil moisture sensor," Agricult. Water Manag., vol. 84, nos. 1-2, pp. 153-165,Jul. 2006.

[12] O. M. Grant, M. J. Davies, H. Longbottom, and C. J. Atkinson, "Irrigation scheduling and irrigation systems: Optimising irrigation efficiencyfor container ornamental shrubs," Irrigation Sci., vol. 27, no. 2, pp. 139-153, Jan. 2009.

[13] Y. Kim, R. G. Evans, and W. M. Iversen, "Remote sensing and control ofan irrigation system using a distributed wireless sensor network," IEEETrans. Instrum. Meas., vol. 57, no. 7, pp. 1379-1387, Jul. 2008.

[14] Y. Kim and R. G. Evans, "Software design for wireless sensorbased site-specific irrigation," Comput. Electron. Agricult., vol. 66, no. 2, pp. 159-165, May 2009. 